\title{
Mucosa-Associated Lymphoid Tissue (MALT) Lymphoma of the Colon in a Patient with Borrelia burgdorferi Infection (Lyme Arthritis)
}

\author{
Timothy Rinden', Juan C. Manivel2,3, Peter A. Valen ${ }^{1,4}$ \\ ${ }^{1}$ Division of Rheumatology, University of Minnesota, Minneapolis, MN, USA \\ ${ }^{2}$ Department of Pathology, Minneapolis VA Medical Center, University of Minnesota, Minneapolis, MN, USA \\ ${ }^{3}$ Department of Pathology, University of Minnesota, Minneapolis, MN, USA \\ ${ }^{4}$ Division of Rheumatology, Minneapolis VA Medical Center, Minneapolis, MN, USA \\ Email: peter.valen@va.gov
}

How to cite this paper: Rinden, T., Manivel, J.C. and Valen, P.A. (2021) MucosaAssociated Lymphoid Tissue (MALT) Lymphoma of the Colon in a Patient with Borrelia burgdorferi Infection (Lyme Arthritis). Case Reports in Clinical Medicine, 10, 403-411.

https://doi.org/10.4236/crcm.2021.1012050

Received: November 5, 2021

Accepted: December 11, 2021

Published: December 14, 2021

Copyright $\odot 2021$ by author(s) and Scientific Research Publishing Inc. This work is licensed under the Creative Commons Attribution International License (CC BY 4.0).

http://creativecommons.org/licenses/by/4.0/

\section{(c) (i) Open Access}

\begin{abstract}
Mucosa-associated lymphoid tissue (MALT) lymphoma generally occurs in the context of chronic inflammation or autoimmune disorders. The most common infections linked to MALT lymphomas include Helicobacter pylori $(\mathrm{Hp})$ associated gastritis, Chlamydophila psittacii and hepatitis C infection. Although Borrelia burgdorferi infection has been linked to primary cutaneous B-cell lymphoma (PCBCL), there is no known link between Borrelia burgdorferi infection and MALT lymphomas in the US. We report a patient who developed mucosa-associated lymphoid tissue (MALT) lymphoma of the colon in the context of untreated Lyme arthritis, and no other autoimmune disorders or infections known to be associated with MALT lymphoma. We recommend that Lyme disease due to Borrelia burgdorferi be considered as a possible underlying infection potentially contributing to the emergence of extranodal lymphoma.
\end{abstract}

Keywords

MALT Lymphoma, Borrelia burgdorferi, Lyme Disease

\section{Introduction}

The non-Hodgkin lymphoma subtype of marginal zone lymphoma represents a group of lymphomas that have been historically classified together because they appear to arise from post-germinal center marginal zone B cells and share a similar immunophenotype. According to the 2008 WHO classification of hematologic malignancies, marginal zone lymphoma (MZL) includes three entities: 
extranodal marginal zone lymphoma (EMZL), nodal marginal zone lymphoma (NMZL) and splenic marginal zone lymphoma (SMZL) [1]. EMZL, also referred to as mucosa-associated lymphoid tissue (MALT)-type lymphoma, is a heterogeneous group of malignancies developing in a variety of organs, including stomach, ocular adnexae, lung, skin, salivary glands, thyroid and breast. EMZLs usually occur in the context of chronic inflammation related to infection or autoimmune disorders.

The first evidence linking EMZL and infection was the observation that Helicobacter pylori $(\mathrm{HP})$-associated gastritis reproduces features of acquired MALT, as well as the high prevalence of $H p$ in gastric MALT lymphoma patients, particularly in endemic regions [2]. This link was further supported by reports of tumor regression in patients treated solely with $H p$-specific antibiotics [3] [4].

More recently, Chlamydophila psittacii infection has been linked to a number of B-cell lymphomas [5]. The most well reported link appears to be with ocular adnexal MALT lymphoma [6], although there is wide geographic variation.

Hepatitis $\mathrm{C}$ infection has been associated with several types of B-cell nonHodgkin's lymphoma (NHL) [7]. HCV infection is seen in half of patients with gastric MALT lymphomas [8], and one third of patients with non-gastric MALT lymphomas [9]. Patients with Sjogren's syndrome and HCV infection frequently develop MALT lymphomas of exocrine glands, liver and stomach [10]. Results from a large Italian study support the use of HCV therapy in HCV-positive patients with indolent B-cell NHL [11].

There is a possible link between primary cutaneous B-cell lymphoma (PCBCL) and Borrelia burgdorferi $(B b)$ infection, primarily in endemic areas of Europe [12]. While DNA of $B b$ has been detected in $10 \%-42 \%$ of patients with PCBCL in Europe [13], studies done in the United States have failed to find convincing evidence of $B b$ DNA in cases of PCBCL [14]. There is also no known link between Lyme disease in the US and EMZL. We report a patient who developed mucosa-associated lymphoid tissue (MALT) lymphoma of the colon in the context of untreated Lyme arthritis, and no other autoimmune disorders or infections known to be associated with MALT lymphoma.

\section{Case Presentation}

A 68-year-old male developed leg swelling and a pulmonary embolus thought to be provoked by a prolonged car trip. A follow-up CTA revealed a right lower lobe pulmonary nodule. A PET/CT was performed, and while the nodule was not hypermetabolic, a PET-avid pericecal mass was found. A CT-guided biopsy of this mass was performed. Microscopic examination revealed small lymphocytes with a nodular pattern of distribution including scattered germinal centers. Immunostains revealed germinal centers positive for $\mathrm{CD} 23$ and bcl6 and negative for $\mathrm{CD} 10$ and bcl2. Ki-67 proliferation index was higher in the germinal centers but very low in the rest of the tissue. The germinal centers were surrounded by B-cells positive for bcl2 and negative for $\mathrm{CD} 5, \mathrm{CD} 10$, and $\mathrm{CD} 43$. 
Rare polyclonal plasma cells were present. Concurrent flow cytometry showed a suggestion of a small population of B-cells with preferential expression of lambda light chains. IgH gene rearrangement study to document clonality was positive. Thus, the morphologic, immunophenotypic, and molecular findings were interpreted as low-grade B-cell lymphoma, best subclassified as marginal zone lymphoma (MZL) (Figure 1). As he was asymptomatic, it was elected to follow him without treatment. He had no known associated infections or auto-immune diseases.

One month later he presented to a walk-in clinic with left knee swelling. $\mathrm{He}$ reported a history of recurrent knee swelling over the prior 3 - 4 years. This had been treated by his primary care provider with short courses of oral corticosteroids, which generally led to resolution of the swelling in a few days. He was referred to rheumatology.

When seen in the rheumatology clinic, he was noted to have a large left knee effusion, but was otherwise asymptomatic. Additional history revealed a prior diagnosis of biopsy-proven psoriasis. Laboratory studies drawn prior to the appointment included a normal CBC, CRP elevated to $77.6 \mathrm{mg} / \mathrm{L}$, and an erythrocyte sedimentation rate (ESR) of $20 \mathrm{~mm} / \mathrm{hr}$. A rheumatoid factor and anti-CCP antibody were negative. HLA-B27 was positive. A knee aspiration with synovial fluid analysis was performed. The fluid contained 51,738 WBC's, 95\% PMNs. Gram stain and routine cultures were negative, as was a crystal exam. Based on his clinical history of psoriasis, synovial fluid exam, and positive HLA-B27, a presumptive diagnosis of peripheral spondyloarthropathy (psoriatic arthritis) was made. The knee was injected with corticosteroid. He reported marked improvement following the aspiration and injection, however the knee effusion recurred 6 weeks later. The knee was re-aspirated, with synovial fluid analysis revealing a WBC count of 11,830 with 90\% PMNs. He was started on sulphasalazine 1 gram twice daily, and a Lyme titer was obtained. The Lyme antibody screen (EIA) returned strongly positive, and a confirmatory IgG immunoblot was positive with 10 out of 10 reactive bands. IgM immunoblot was non-reactive. Following this result, the patient was recalled to clinic. The knee was re-aspirated and a synovial fluid sample was sent for Borrelia DNA PCR, which returned positive. The sulfasalazine was stopped, and he was placed on doxycycline for 4 weeks, with resolution of his knee swelling.

He had ongoing follow-up in Hematology/Oncology for his MALT lymphoma. A follow-up PET/CT 9 months later revealed an increase in size of the peri-cecal mass and several hypermetabolic masses within the abdomen and pelvis. A moderately hypermetabolic nodule was seen in the right lower lobe. A repeat biopsy of the peri-cecal mass revealed continuous evidence of involvement by low-grade B-cell lymphoma, consistent with MZL. A follow-up CT revealed an increase in size of the RLL nodule, however upon further review of serial scans, it appeared to wax and wane in size, and the consensus was that it represented an extra-abdominal site of lymphoma rather than a primary lung cancer. It was 


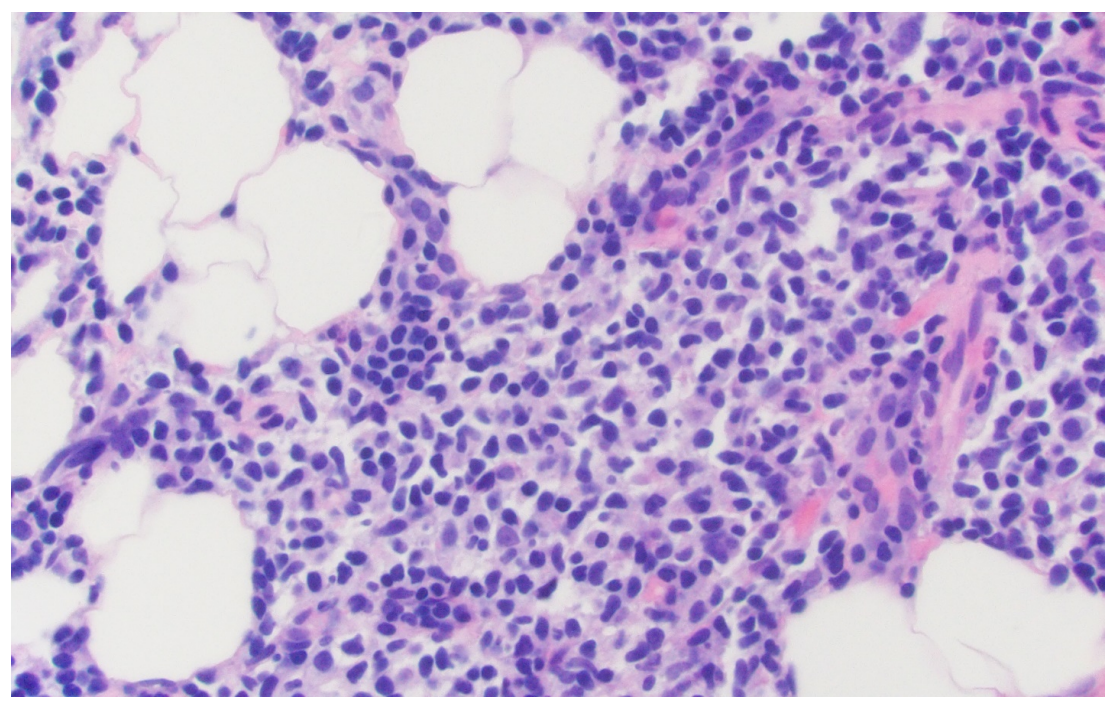

Figure 1. Pericecal adipose tissue shows dense infiltrate composed of small lymphocytes, centrocyte-like cells and monocytoid cells (Hematoxylin and eosin stain, original magnification $600 \times$ ).

not felt to be amenable to biopsy due to its proximity to the diaphragm. He received 3 fractions of stereotactic ablation radiotherapy (SBRT). A follow-up CT revealed resolution of this nodule. It was felt that due to continued lack of symptoms and no spleen involvement, his MZL did not need therapy.

When seen 6 months later, a PET/CT revealed improvement in multiple hypermetabolic masses in the chest, abdomen and pelvis suggesting decreasing viable lymphoma, however there was progression noted in the size and hypermetabolism of a retroperitoneal mass. He remained asymptomatic, and therapy was deferred.

4 months later he was admitted for abdominal and flank pain. A CT revealed substantial enlargement of the retroperitoneal mass with new posterior mediastinal and right paraspinal masses suggesting disease progression. A retroperitoneal biopsy revealed a diffuse large B-cell lymphoma (DLBCL) of germinal center origin and no morphologic or immunophenotypic evidence of his previously diagnosed MZL. Furthermore, while his previous low-grade lymphoma was lambda-restricted, the retroperitoneal lymphoma was kappa-restricted. B-cell clonality studies were performed to evaluate for clonal relatedness to the prior low-grade B-cell lymphoma; the IgH immunoglobulin gene rearrangement detected in the retroperitoneum was different from that identified in the paracecal mass and also favored a separate process. He received 6 courses of R-CHOP chemotherapy (rituximab, cyclophosphamide, doxorubicin, vincristine and prednisone). A follow-up PET/CT revealed radiographic complete remission, with no FDG-avid lesions to suggest viable high-grade lymphoma. He currently feels well, and has had no recurrence of his Lyme arthritis.

\section{Discussion}

Borrelia burgdorferi $(B b)$ is the causative agent of Lyme disease in North Amer- 
ica, while Borrelia afzelii and Borrelia garinii are the primary causative agents in Europe and Asia. The interest in a possible link between primary cutaneous B-cell lymphoma (PCBCL) and Borrelia infection stemmed from the historical association of acrodermatitis chronica atrophicans (ACA), a late cutaneous manifestation of Lyme disease in Europe, with cutaneous lymphoma [15]. A number of studies have further supported this link. In a study from Belgrade, 15 of 22 (55\%) patients with primary cutaneous B-cell lymphoma had positive Borrelia serology, compared to $4.6 \%$ in the control group [12]. Two serologically positive patients had ACA and one had arthritis. In a study from an endemic area of Scotland the authors looked for evidence of $B b$ in 20 cases of PCBCL and 40 control patients. A nested PCR was performed on DNA extracts from the lymphoma and control cases using primers to a unique conserved region of the $B b$ flagellin gene. $B b$-specific DNA was detected in 7 of 20 lymphoma cases (5 of 12 MZL, 1 of 5 primary cutaneous follicular center cell lymphomas, and 1 of 3 diffuse, large B-cell lymphomas) and in one melanoma patient [16]. An investigator in Germany reported six patients with low-grade cutaneous B-cell lymphoma and chronic $B b$ infection [17]. In a report from France, the authors reported finding Borrelia DNA by PCR in the tissue of 3 of 16 cases of cutaneous MALT lymphoma [18]. Two of the three PCR-positive patients had lymphoma located on the nipple. Interestingly, this location along with the ear lobe are common sites of involvement in early Lyme disease in Europe, and have been referred to as borrelial lymphocytomas. A recent meta-analysis attempted to further analyze the association between $B b$ and PCBCL [19]. Ten studies with 506 primary cutaneous lymphomas (PCL) and 201 controls were included. Borrelia DNA positivity was significantly associated with PCL $(\mathrm{OR}=10.88$; $\mathrm{p}<0.0001)$. The prevalence of Borrelia DNA positivity was similar among different entities (MZL: 7.3\%, follicular: $8.1 \%$, DLBCL: $7.5 \%$, mycosis fungoides (MF): $8 \%$ ) There was notable geographic variability, with the highest association in endemic areas. Out of the eleven reported cases of PCBCL treated with antibiotics, 6 responded and 5 didn't. The six responders were positive for Borrelia DNA on PCR assays, while the 5 non-responders were only positive for Borrelia antibodies.

As noted, the majority of reports of $B b$-associated PCBCL come from endemic areas of Europe. Studies done in the United States thus far have failed to find convincing evidence of $B b$-specific DNA in studied cases of PCBCL [13].

There is evidence supporting the use of antibiotics as primary therapy for MZL. H pylori eradication has been advocated as initial therapy for gastric MALT lymphoma [20]. Although initial therapy for primary ocular adnexal MALT lymphoma (POAML) is involved field radiation therapy, antibiotic therapy may be an alternative treatment. Several studies have demonstrated safety and efficacy of doxycycline in chlamydia-positive POAML [21] [22] [23]. There are conflicting reports on the efficacy of antibiotic treatment of $B b$ infection in cutaneous MZL [24] [25].

An association between extra-gastric MALT lymphoma of the small intestine 
and Campylobacter jejuni infection has been reported [26] [27]. An infectious etiology has not been established, however, for colonic MALT lymphoma [28].

Our patient had a history of hepatitis C (HCV) infection, which is known to be associated with MZL. In addition to splenic MZL, HCV infected patients can develop a disseminated type of MZL [29]. Our patient had been treated with ledipasvir/sofosbuvir (Harvoni) however, and his HCV viral load had been undetectable for four years. It appears that chronic active rather than cleared HCV infection is required for lymphomagenesis [30].

Our patient was also HLA-B27 positive. While it has been suggested that Lyme arthritis could potentially represent a peripheral spondyloarthropathy (reactive arthritis), our patient did not have any additional spondyloarthropathy features. No evidence of sacroiliitis was seen on pelvic CT, and the synovial fluid aspirate contained Borrelia DNA. There is very little literature on this subject. Weyand et al convincingly demonstrated circulating antibodies and proliferative $\mathrm{T}$ cell responses to $B b$ in $18 \%$ of patients with reactive arthritis in an endemic area [31]. However, in another study from Germany, the frequencies of HLA-A, B, Cw and DR were analyzed in 283 persons from Austria and Germany with manifest $B b$ infection [32]. No statistically significant differences were found between patients and control groups with regards to the frequencies of particular HLA antigens. The presence of HLA-DR4 and DR2 alleles has been associated with treatmentresistant Lyme arthritis in the US, however [33].

\section{Conclusion}

In summary, we present a case of mucosa-associated lymphoid tissue (MALT) lymphoma of the large intestine occurring in a patient with chronic Lyme arthritis, and no other underlying infections or autoimmune diseases known to be associated with lymphoma. His MALT lymphoma remained stable following antibiotic therapy for Lyme arthritis. Three years later, he developed a diffuse large B-cell lymphoma that was morphologically and immunophenotypically distinct from his prior MALT lymphoma. It is not possible to confirm a cause and effect relationship between his lymphoma and Lyme disease. It would have been interesting to look for Borrelia burgdorferi DNA in his initial tumor tissue; however, PCR assay for Borrelia on paraffin embedded tissue is not readily available. We would recommend that Lyme disease due to Borrelia burgdorferi be considered as a possible underlying infection potentially contributing to the emergence of extranodal lymphoma.

\section{Conflicts of Interest}

The authors declare no conflicts of interest regarding the publication of this paper.

\section{References}

[1] Jaffe, E.S. (2009) The 2008 WHO Classification of Lymphomas: Implications for 
Clinical Practice and Translational Research. Hematology, American Society of Hematology Education Program, 2009, 523-531.

https://doi.org/10.1182/asheducation-2009.1.523

[2] Doglioni, C., Wotherspoon, A.C., Moschini, A., de Boni, M. and Isaacson, P.C. (1992) High Incidence of Primary Gastric Lymphoma in Northeastern Italy. Lancet, 339, 834-835. https://doi.org/10.1016/0140-6736(92)90280-G

[3] Wotherspoon, A.C., Doglioni, C., Diss, T.C., Pan, L.X., Moschini, A., et al. (1993) Regression of low Grade B-Cell Gastric Lymphoma of MALT Type Following Eradication of Helicobacter pylori (Meeting Abstract). The Journal of Pathology, 170, $335 \mathrm{~A}$.

[4] Hancock, B.W., Qian, W., Linch, D., Delchier, J.C., Smith, P., et al. (2009) Chlorambucil versus Observation after Anti-Helicobacter Therapy in Gastric MALT Lymphomas: Results of the International Randomized LY03 Trial. British Journal of Haematology, 144, 367-375. https://doi.org/10.1111/j.1365-2141.2008.07486.x

[5] Ponzoni, M., Ferreri, A.J., Guidoboni, M., Lettini, A.A., Cangi, M.G., et al. (2008) Chlamydia Infection and Lymphomas: Association beyond Ocular Adnexal Lymphomas Highlighted by Multiple Detection Methods. Clinical Cancer Research, 14, 5794-5800. https://doi.org/10.1158/1078-0432.CCR-08-0676

[6] Ferreri, A.J.M., Guidoboni, M., Ponzoni, M., De Conciliis, C., Dell’Oro, S., Fleischhauer, K., et al. (2004) Evidence for an Association between Chlamydia psittaci and Ocular Adnexal Lymphomas. Journal of the National Cancer Institute, 96, 586-594. https://doi.org/10.1093/jnci/djh102

[7] Marcucci, F. and Mele, A. (2011) Hepatitis Viruses and Non-Hodgkin Lymphoma: Epidemiology, Mechanisms of Tumorigenesis, and Therapeutic Opportunities. Blood, 117, 1792-1798. https://doi.org/10.1182/blood-2010-06-275818

[8] Luppi, M., Longo, G., Ferrari, M.G., Ferrara, L., Marasca, R., Barozzi, P., et al. (1996) Additional Neoplasms and HCV Infection in Low-Grade Lymphoma of MALT Type. British Journal of Haematology, 94, 373-375. https://doi.org/10.1046/j.1365-2141.1996.d01-1791.x

[9] Arcaini, L., Burcheri, S., Rossi, A., Paulli, M., Bruno, R., et al. (2007) Prevalence of HCV Infection in Nongastric Marginal Zone B-cell Lymphoma of MALT. Annals of Oncology, 18, 346-350. https://doi.org/10.1093/annonc/mdl388

[10] Ramos-Casals, M., Trejo, O., Garcia-Carrasco, M., Cervera, R., De, La Red, G., et al. (2004) Triple Association between Hepatitis C Virus Infection, Systemic Autoimmune Diseases, and B Cell Lymphoma. Journal of Rheumatology, 31, 495-499. https://doi.org/10.1093/annonc/mdl388

[11] Kelaidi, C., Rollot, F., Park, S., Tulliez, M., Christoforov, B., Calmus, Y., et al. (2004) Response to Antiviral Treatment in Hepatitis C Virus-Associated Marginal Zone Lymphomas. Leukemia, 18, 1711-1716. https://doi.org/10.1038/sj.leu.2403443

[12] Jelic, S. and Filipovic-Ljeskovic, I. (1999) Positive Serology for Lyme Disease Borrelias in Primary Cutaneous B-Cell Lymphoma: A Study in 22 Patients; Is It a Fortuitous Finding? Hematological Oncology, 17, 107-116.

https://doi.org/10.1002/(SICI)1099-1069(199909)17:3\%3C107::AID-HON644\%3E3. $\underline{0 . \mathrm{CO} ; 2-\mathrm{R}}$

[13] Ferreri, A.M., Govi, S. and Ponzoni, M. (2013) Marginal Zone Lymphomas and Infectious Agents. Seminars in Cancer Biology, 23, 431-440. https://doi.org/10.1016/j.semcancer.2013.09.004

[14] Wood, G.S., Kamath, N.V., Guitart, J., Heald, P., Kohler, S., et al. (2001) Absence of Borrelia burgdorferi DNA in Cutaneous B-Cell Lymphomas from the United States. 
Journal of Cutaneous Pathology, 28, 502-507. https://doi.org/10.1034/j.1600-0560.2001.281002.x

[15] Goos, M. (1971) Acrodermatitis Chronica Atrophicans and Malignant Lymphoma. Acta Dermato- Venereologica, 51, 457-459.

[16] Goodlad, J.R., Davidson, M.M., Hollowood, K., Ling, C., MacKenzie, C., et al. (2000) Primary Cutaneous B-Cell Lymphoma and Borrelia burgdorferi Infection in Patients from the Highlands of Scotland. American Journal of Surgical Pathology, 24, 1279-1285. https://doi.org/10.1097/00000478-200009000-00012

[17] Garbe, C., Stein, H., Dienemann, D. and Orfanos, C.E. (1991) Borrelia burgdorferi-Associated Cutaneous B Cell Lymphoma: Clinical and Immunohistologic Characterization of Four Cases. Journal of the American Academy of Dermatology, 24, 584-590. https://doi.org/10.1016/0190-9622(91)70088-J

[18] Fouchardiere, A., Vandenesch, F. and Berger, F. (2003) Borrelia-Associated Primary Cutaneous MALT Lymphoma in a Nonendemic Region. American Journal of Surgical Pathology, 27, 702-703. https://doi.org/10.1097/00000478-200305000-00017

[19] Travaglino, A., Varricchio, S., Pace, M., Russo, D., Picardi, M., et al. (2020) Borrelia Burgdorferi in Primary Cutaneous Lymphomas: A Systematic Review and MetaAnalysis. JDDG: Journal der Deutschen Dermatologischen Gesellschaft, 12, 13791384. https://doi.org/10.1111/ddg. 14289

[20] Zucca, E., Copie-Bergman, C., Ricardi, U., Thieblemont, C., Raderer, M., et al. (2013) Gastric Marginal Zone Lymphoma of MALT Type: ESMO Clinical Practice Guidelines for Diagnosis, Treatment and Follow-up. Annals of Oncology, 24, vi144-vi148. https://doi.org/10.1093/annonc/mdt343

[21] Ferreri, A.J., Ponzoni, M., Guidoboni, M., Resti, A.G., Politi, L.S., et al. (2006) Bacteria-Eradicating Therapy with Doxycycline in Ocular Adnexal MALT Lymphoma: A Multicenter Prospective Trial. Journal of the National Cancer Institute, 98, 1375 1382. https://doi.org/10.1093/jnci/dji373

[22] Ferreri, A.N., Govi, S., Pasini, E., Mappa, S., Bertoni, F., et al. (2012) Chlamydophila psittaci Eradication with Doxycycline as First-Line Targeted Therapy for Ocular Adnexae Lymphoma: Final Results of an International Phase II Trial. Journal of Clinical Oncology, 30, 2988-2994. https://doi.org/10.1200/JCO.2011.41.4466

[23] Han, J.J., Kim, T.M., Jeon, Y.K., Kim, M.K., Khwarg, S.I., et al. (2015) Long-Term Outcomes of First-Line Treatment with Doxycycline in Patients with Previously Untreated Ocular Adnexal Marginal Zone B Cell Lymphoma. Annals of Hematology, 94, 575-581. https://doi.org/10.1007/s00277-014-2240-8

[24] Kiesewetter, K.B. and Raderer, M. (2013) Antibiotic Therapy in Nongastrointestinal MALT Lymphoma: A Review of the Literature. Blood, 122, 1350-1357.

https://doi.org/10.1182/blood-2013-02-486522

[25] Kutting, B., Bonsmann, G., Metze, D., Luger, T.A. and Cerroni, L. (1997) Borrelia burgdorferi-Associated Primary Cutaneous B Cell Lymphoma: Complete Clearing of Skin Lesions after Antibiotic Pulse Therapy or Intralesional Injection of Interferon alfa-2a. Journal of the American Academy of Dermatology, 36, 311-314. https://doi.org/10.1016/S0190-9622(97)80405-7

[26] Shaye, O.S. and Levine, A.M. (2006) Marginal Zone Lymphoma. Journal of the National Comprehensive Cancer Network, 4, 311-318. https://doi.org/10.6004/jnccn.2006.0026

[27] Piotrowski, R., Kramer, R. and Kamal, A. (2008) Image of the Month. Extranodal Marginal Zone B-Cell (Mucosa-Associated Lymphoid Tissue) Lymphoma of the Colon Presenting as an Obstructing Mass. Clinical Gastroenterology and Hepatolo- 
gy, 6, e18-e19. https://doi.org/10.1016/j.cgh.2007.12.033

[28] Romaguera, J. and Hagemeister, F.B. (2005) Lymphoma of the Colon. Current Opinion in Gastroenterology, 21, 80-84.

[29] Mollejo, M., Menarguez, J., Guisado-Vasco, P., Bento, L., Algara, P., et al. (2014) Hepatitic C Virus-Related Lymphoproliferative Disorders Encompass a Broader Clinical and Morphological Spectrum than Previously Recognized: A Clinicopathological Study. Modern Pathology, 27, 281-293.

https://doi.org/10.1038/modpathol.2013.120

[30] Paydas, S. (2015) Hepatitis C Virus and Lymphoma. Critical Reviews in Oncology/Hematology, 93, 246-256. https://doi.org/10.1016/j.critrevonc.2014.10.008

[31] Weyand, C.M. and Goronzy, J.J. (1989) Immune Responses to Borrelia burgdorferi in Patients with Reactive Arthritis. Arthritis \& Rheumatism, 32, 1057-1064. https://doi.org/10.1002/anr.1780320902

[32] Reimers, C.D., Neubert, U., Kristoferitsch, W., Pfluger, K.H. and Mayr, W.R. (1992) Borrelia burgdorferi Infection in Europe: An HLA-Related Disease. Infection, 20, 197-200. https://doi.org/10.1007/BF02033058

[33] Steere, A.C., Dwyer, E. and Winchester, R. (1990) Association of Chronic Lyme Arthritis with HLA-DR4 and HLA-DR2 Alleles. New England Journal of Medicine, 323, 219-223. https://doi.org/10.1056/NEJM199007263230402 